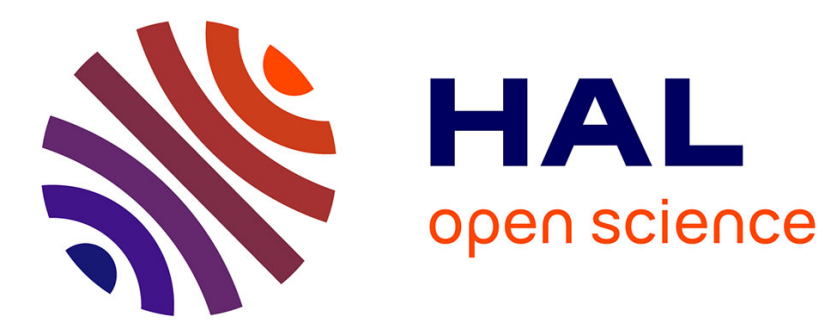

\title{
Big Data Analytics as a Service for Business Intelligence
}

\author{
Zhaohao Sun, Huasheng Zou, Kenneth Strang
}

\section{To cite this version:}

Zhaohao Sun, Huasheng Zou, Kenneth Strang. Big Data Analytics as a Service for Business Intelligence. 14th Conference on e-Business, e-Services and e-Society (I3E), Oct 2015, Delft, Netherlands. pp.200-211, 10.1007/978-3-319-25013-7_16 . hal-01448039

\section{HAL Id: hal-01448039 \\ https://hal.inria.fr/hal-01448039}

Submitted on 27 Jan 2017

HAL is a multi-disciplinary open access archive for the deposit and dissemination of scientific research documents, whether they are published or not. The documents may come from teaching and research institutions in France or abroad, or from public or private research centers.
L'archive ouverte pluridisciplinaire HAL, est destinée au dépôt et à la diffusion de documents scientifiques de niveau recherche, publiés ou non, émanant des établissements d'enseignement et de recherche français ou étrangers, des laboratoires publics ou privés. 


\title{
Big Data Analytics as a Service for Business Intelligence
}

\author{
Zhaohao Sun ${ }^{1}$, Huasheng Zou ${ }^{2}$, Kenneth Strang ${ }^{3}$ \\ ${ }^{1}$ Department of Business Studies \\ PNG University of Technology, Lae 411, PNG \\ zsun@dbs.unitech.ac.pg; zhaohao.sun@gmail.com \\ ${ }^{2}$ College of e-Commerce, \\ Ningbo Dahongying University, Ningbo, Zhejiang 315175, China \\ zoufan99@163.com \\ ${ }^{3}$ School of Business \& Economics \\ State University of New York, Plattsburgh at Queensbury, NY 12804, USA \\ kenneth.strang@plattsburgh.edu
}

\begin{abstract}
This paper proposes an ontology of big data analytics and examines how to enhance business intelligence through big data analytics as a service by presenting a big data analytics services-oriented architecture (BASOA), and applying BASOA to business intelligence, where our surveyed data analysis showed that the proposed BASOA is viable for developing business intelligence and enterprise information systems. This paper also discusses the interrelationship between business intelligence and big data analytics. The proposed approach in this paper might facilitate the research and development of business analytics, big data analytics, and business intelligence as well as intelligent agents.
\end{abstract}

Keywords: big data analytics, e-commerce, business intelligence, intelligent agents.

\section{Introduction}

Big data and big data analytics has become one of the important research frontiers [1]. Big data and its emerging technologies including big data analytics have been not only making big changes in the way the e-commerce and e-services operate but also making traditional data analytics and business analytics bring new big opportunities for academia and enterprises [2]. Big data analytics is an emerging big data technology, and has become a mainstream market adopted broadly across industries, organizations, and geographic regions and among individuals to facilitate data-driven decision making for business and individual's hedonism [3] [4].

Business intelligence (BI) has received widespread attention in academia, ecommerce, and business over the past two decades [5]. BI has become not only an important technology for improving business performance of enterprises but also an impetus for developing e-commerce and e-services (Turban \& Volonino, 2011). However, BI is facing new challenges and opportunities because of dramatic development of big data and big data technologies [6, 7]; that is, how to use big data 
analytics to enhance BI become a big issue for business, e-commerce, e-services, and information systems.

Big data analytics and BI are the top priorities of chief information officers (CIOs) and comprise a $\$ 12.2$ billion market [8]. According to a study of Gartner, worldwide BI and analytics software, consisting of BI platforms, analytic applications and advanced analytics, totalled $\$ 14.4$ billion in 2013, an $8 \%$ increase from 2012 revenue [9]. This fact attracts unprecedented interest and adoption of big data analytics. According to the annual survey results of $850 \mathrm{CEO}$ and other C-level executives of global organisations, McKinsey (2014) concludes that $45 \%$ of executives put "big data and advanced analytics" as the first three strategic priorities in both strategy and spending in three years' time and more than one thirds of executives will now spend or in three years' time in this area. IDC (International Data Corporation) predicts that the business analytics software market will grow at a 9.7\% compound annual growth rate over the next five years from 2012 to 2017 [4].

The above brief discussion and literature review implies that there is a close relationship between big data analytics and BI. However, the following two important issues have not been drawn significant attention in the scholarly peer-reviewed literature:

- What is the relationship between big data analytics and BI?

- How can big data analytics enhance BI?

This paper will address these two issues through extending our early research on analytics service oriented architecture [2]. To address the first issue, we propose an ontology of big data analytics in section 2 through overviewing our early work on data analytics and big data analytics. To address the second issue, we examine big data analytics as a technology for supporting BI through examining the relationship between big data analytics and BI in Section 3. We then present a big data analytics service oriented architecture (BASOA), in which we also explore how to apply big data analytics as a service to enhance BI, where we show that the proposed BASOA is viable for developing BI based on our surveyed data analysis.

The remainder of this paper is organized as follows. Section 2 looks at the fundamentals of big data analytics by proposing an ontology of big data analytics and discussing the relationships of big data analytics and data analytics. Section 3 discusses BI and its relationships with big data analytics. Section 4 presents BASOA. Section 5 applies proposed BASOA to BI. The final sections discuss the related work and end this paper with some concluding remarks and future work.

\section{Fundamentals of Big Data Analytics}

This section proposes an ontology of big data analytics and looks at the interrelationship between big data analytics and data analytics. To begin with, this section first examines the fundamentals of big data analytics.

Big data analytics is an integrated form of data analytics and web analytics for big data [2]. According to [7] and [10], big data analytics can be defined as the process of collecting, organizing and analyzing big data to discover patterns, knowledge, and intelligence as well as other information within the big data. Similarly, big data 
analytics can be defined as techniques used to analyze and acquire knowledge and intelligence from big data [7]. Big data analytics is an emerging science and technology involving the multidisciplinary state-of-art information and communication technology (ICT), mathematics, operations research (OR), machine learning (ML), and decision sciences for big data $[2,1]$. The main components of big data analytics include big data descriptive analytics, big data predictive analytics and big data prescriptive analytics [11].

- Big data descriptive analytics is descriptive analytics for big data [12], and is used to discover and explain the characteristics of entities and relationships among entities within the existing big data [13, p. 611]. It addresses the problems such as what happened, and when, as well as what is happening. For example, web analytics for pay-per-click or email marketing data belongs to big data descriptive analytics [14].

- Big data predicative analytics is predicative analytics for big data, which focuses on forecasting trends by addressing the problems such as what will happen, what is likely to happen and why it will happen [12] [15]. Big data predicative analytics is used to create models to predict future outcomes or events based on the existing big data [13, p. 611]. For example, big data predicative analytics can be used to predict where might be the next attack target of terrorists.

- Big data prescriptive analytics is prescriptive analytics for big data, which addresses the problems such as what we should do, why we should do it and what should happen with the best outcome under uncertainty [11, p. 5]. For example, big data prescriptive analytics can be used to provide an optimal marketing strategy for an e-commerce company.

An ontology is a formal naming and definition of a number of concepts and their interrelationships that really or fundamentally exist for a particular domain of discourse [16]. Then, an ontology of big data analytics is an investigation into a number of concepts and their interrelationships that fundamentally exist for big data analytics. Based on the above discussion, we propose an ontology of big data analytics, as illustrated in Figure 1. In this ontology, big data analytics is at the top while big data and data analytics are at the bottom. Big data descriptive analytics, big data predictive analytics, and big data prescriptive analytics are at the middle level as the core parts of any big data analytics.

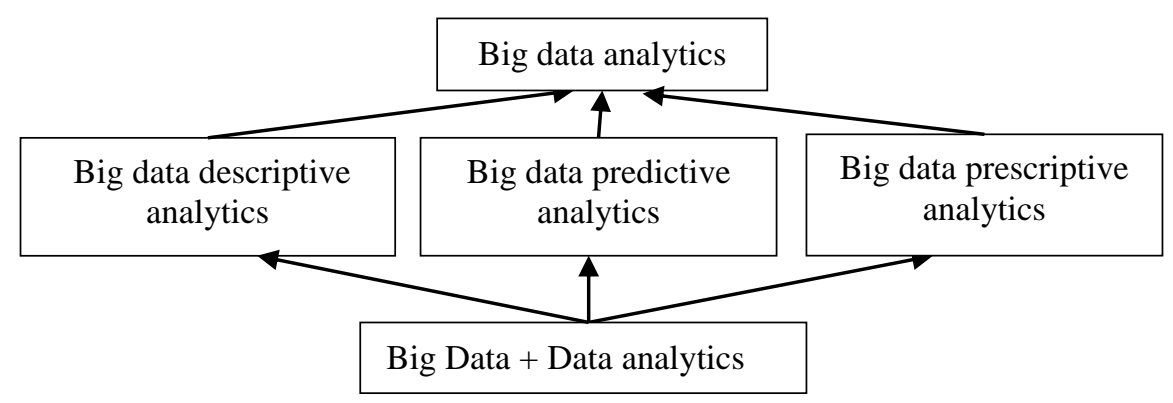

Figure 1. An ontology of big data analytics 
It should be noted that the above-proposed ontology of big data analytics is still simple. We will extend it by adding another level between the second level and the third level in Figure 1. This added level will elaborate big data descriptive, predictive and prescriptive analytics taking into account the corresponding real-world examples, methods and techniques.

In Figure 1, data analytics refers to as a method or technique that uses data, information, and knowledge to learn, describe and predict something [15, p. 341]. In brief, data analytics can be then considered as data-driven discoveries of knowledge, intelligence and communications [12]. More generally, data analytics is a science and technology about examining, summarizing, and drawing conclusions from data to learn, describe and predict something [2].

The fundamentals of big data analytics consists of mathematics, statistics, engineering, human interface, computer science and information technology $[2,1]$. The techniques for big data analytics encompass a wide range of mathematical, statistical, and modeling techniques [13, p. 590]. Big data analytics always involves historical or current data and visualization [17]. This requires big data analytics to use data mining (DM) to discover knowledge from a data warehouse (DW) or a big dataset in order to support decision making, in particular in the text of big business and management [15, p. 344]. DM employs advanced statistical tools to analyze the big data available through DWs and other sources to identify possible relationships, patterns and anomalies and discover information or knowledge for rational decision making [13, p. 590]. DW extracts or obtains its data from operational databases as well as from external open sources, providing a more comprehensive data pool including historical or current data [13, p. 590]. Big data analytics also uses statistical modelling (SM) to learn something that can support decision making [2]. Visualization techniques as an important part of big data analytics make knowledge patterns and information for decision making in a form of figure or table or multimedia. In summary, big data analytics can facilitate business decision making and realization of business objectives through analyzing current problems and future trends, creating predictive models to forecast future threats and opportunities, and analyzing/optimizing business processes based on involved historical or current data to enhance organizational performance using the mentioned techniques [12]. Therefore, big data analytics can be represented below.

$$
\text { Big data analytics }=\text { Big data }+ \text { data analytics }+ \text { DW }+ \text { DM + }
$$
$\mathrm{SM}+\mathrm{ML}+$ Visualization+ optimization

Where + can be explained as "and". This representation reveals the fundamental relationship between big data, data analytics and big data analytics, that is, big data analytics is based on big data and data analytics, as illustrated in Figure 1. It also shows that computer science and information technology play a dominant role in the development of big data analytics through providing sophisticated techniques and tools of DM, DW, ML and visualization [2]. SM and optimization still plays a fundamental role in the development of big data analytics, in particular in big data prescriptive analytics [11].

It should be noted that the above equation is a concise representation for the technological components of big data analytics whereas the proposed ontology of big 
data analytics in this Section is to look at what big data analytics constitutes at a relatively high level. We will consider the big data descriptive, predictive and prescriptive analytics as one dimension, and the technological components of big data analytics as another dimension. Then we will provide this 2-dimension analysis as a future research work.

\section{Business Intelligence and Big Data Analytics}

This section will examine business intelligence (BI) and its relationships with big data analytics.

BI has drawn increasing attention in academia and business over the past two decades, although the term was already coined in 1958 by an IBM scientist [18]. There are many different definitions on BI. For example,

- $\quad$ BI is defined as providing decision makers with valuable information and knowledge by leveraging a variety of sources of data as well as structured and unstructured information [19].

- $\quad$ BI refers to as a collection of information systems (IS) and technologies that support managerial decision makers of operational control by providing information on internal and external operations [15].

- $\quad$ BI is a framework consisting of a set of concepts, theories, and methods to improve business decision making by using fact-based support systems [5].

The first definition of BI emphasizes information and knowledge for decision makers. The second definition stresses "a collection of ISs and technologies" while specifies the decision makers to "managerial decision makers of operational control", and information to "information on internal and external operations". The last definition emphasizes "a set of concepts, theories, and methods to improve business decision making". Based on the above analysis, BI can be defined as a set of theories, methodologies, architectures, systems and technologies that support business decision making with valuable data, information and knowledge. This definition reflects the evolution of BI and its technologies from decision support systems (DSS) and its relations with data warehouses, executive information systems [8].

The principal tools for BI include software for database query and reporting (e.g. SAP ERP, Oracle ERP, etc.), tools for multidimensional data analysis (e.g. OLAP), and data mining (e.g. predictive analysis, text mining, web mining) [20]. Data warehousing is also considered as a foundation of BI [5].

Based on the previous subsection's discussion, big data analytics can be considered a part of BI [5], because it "supports business decision making with valuable data, information and knowledge" [2]. Both BI and big data analytics are common in emphasizing either valuable data or information or knowledge. BI involves interactive visualization for data exploration and discovery, for them Tableau, QlikView and Tibco's Spotfire are BI tools for interactive visualization for data exploration and discovery [21]. These BI tools are also considered as the tools of big data analytics. This implies that BI and big data analytics share some common tools to support business decision making. 
Currently, BI is based on four cutting-age technology pillars of cloud, mobile, big data and social technologies [22] [17], each of these pillars corresponds to a special kind of web services, that is, cloud services, mobile services, big data services and social networking services; all these constitute modern web services [17]. Each of these services has been supported by analytics services and technologies [2]. They are effectively supported also by big data analytics as a service and technology, as shown in Figure 2.

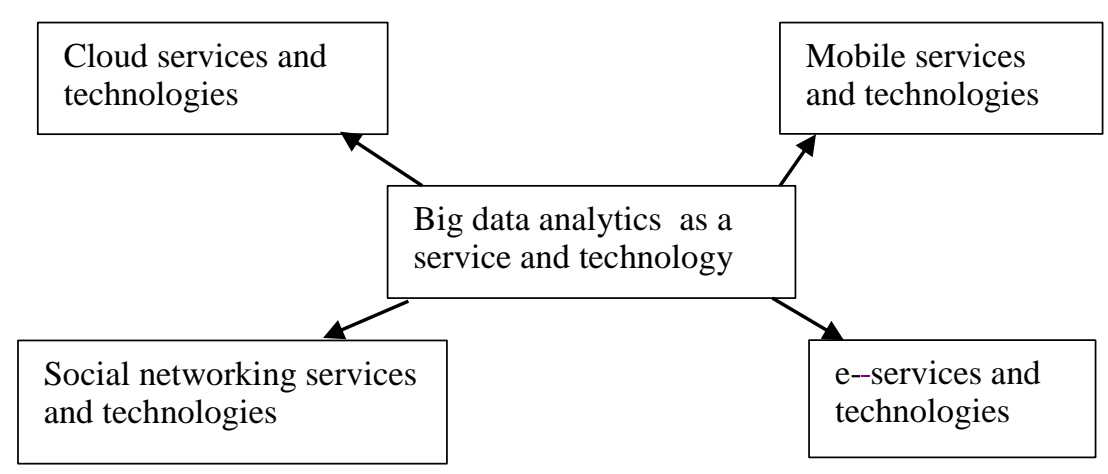

Figure 2. Interrelationship between big data analytics and web services [2]

It should be noted that for the state-of-art web services, Sun and Yearwood [17] explores that web services mainly consist of mobile services, analytics services, cloud services, social networking services, and service as a web service. In reality, each of them involves sophisticated ICT technologies. Then, technologies are added to mobile services, analytics services, cloud services and social networking services in [2]. Here we emphasize big data analytics as a service and technology at the center to support cloud services and technologies, social networking services and technologies, mobile services and technologies, e-services and technologies to reflect the big data and analytics as an emerging new service and technology. The readers can easily find practical examples to reflect this trend. We do not go into it anymore because of limitation of space.

Based on IDC's prediction for the IT market in 2014 [22], spending on big data will explode and grow by $30 \%$, to $\$ 14+$ billion, in which, big data analytics services will experience an explosive growth. The spending on big data analytics services will exceed $\$ 4.5$ billion, growing $21 \%$. The number of providers of big data analytics services will triple in three years. This means that big data analytics as a service and technology has become an important emerging market, together with cloud services, mobile services and social networking services [2]. All these four services and the technologies shape the most important markets for e-commerce and e-services [17].

Furthermore, BI is a more general concept for improving business performance and business decision making. Big data analytics is a pivotal part for developing BI, at least from a technological viewpoint and data viewpoint. From a technological viewpoint, big data analytics is data-driven and business oriented technique and facilitates business decision making and then improves BI [2]. From a data viewpoint, 
big data analytics relies on data analytics and big data which have become a strategic natural resource for every organization, in particular for multinational organizations as well as for e-commerce and e-services. Discovering secrets from data bases, data warehouses, data marts and the Web has become the central topics for business operations, marketing and BI. This is just the task of big data analytics.

\section{BASOA: Big Data Analytics Services Oriented Architecture}

This section proposes a big data analytics service oriented architecture (BASOA) and then examines each of the main players in the BASOA. Different from the traditional SOA [23], the proposed BASOA is specifying general services to big data analytics services, as showing in Figure 3. We use BA in this architecture, BASOA, to represent big data analytics, which implies that big analytics (BA) can represent big data analytics briefly. This is reasonable because we have big data and big analytics, both are originally from data and analytics respectively.

In this BASOA, big data analytics service provider, big data analytics service requestor, big data analytics service broker are three main players. In what follows, we will look at each of these in some detail, taking into account BI.

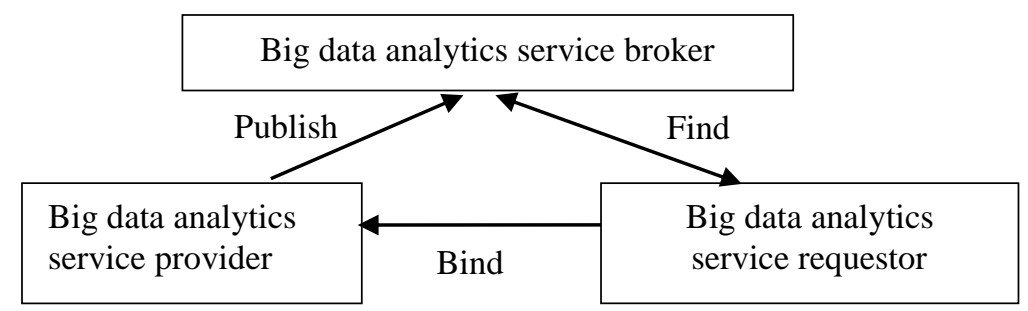

Figure 3. BASOA: A big data analytics SOA

Big data analytics service requestors include organizations, governments and all level business decision makers such as CEO, CIO and CFO as well as managers. Big data analytics service requestors also include business information systems and ecommerce systems. Big data analytics service requestors require big data analytics services including information analytics services, knowledge analytics services, business analytics services with visualization techniques to provide knowledge patterns and information for decision making in a form of figure or table or report [24]. More generally, big data analytics service requestors include people who like to make decisions or acquire information based on analytical reports provided by big data analytics service provider [2]. Therefore, a person with smartphone receiving analytics services is also a big data analytics service requestor [12].

Big data analytics service brokers are all the entities that facilitate the development of big data analytics services, which include popular presses, traditional media and social media, consulting companies, scholars and university students, and so on [2]. All these use a variety of methods and techniques to improve the better understanding of big data analytics services in general and data analytics, business analytics, web analytics, and their services in particular [2]; all these have been offered to university students as a course material or content in business and computing areas to some 
extent in recent years. McKinsey Consulting (http://www.mckinsey.com/), Boston Consulting Group (BCG), and IDC as big data analytics service brokers have played an important role in pushing big data analytics in businesses and enterprises, just as they promote "big data". Gartner and Forrester are also famous big data analytics service brokers in the world [12].

Big data analytics service providers include analytics developers, analytics vendors, analytics systems or software and other intermediaries that can provide analytics services. Recently, web analytics service (WAS) providers are important big data analytics service providers. A WAS provider, for example, Adobe Marketing Cloud (http://www.adobe.com/au/solutions/digital-marketing.html), aggregates and analyses blog data about the online behaviors of users who visited the client's website, then they evaluate a variety of analytical reports concerning the client's customer online behaviors that the client wishes to understand. This can then facilitate their strategic business decision making [25]. Application service providers (ASPs) can also provide web analytics in a hosted ASP model with quicker implementation and lower administrative costs [25]. Analytics developers provide analytic tools with extensive data extraction, analytics and reporting functionality such as Piwik, CrawlTrack [26]. Google is not only a search engine provider, but also a WAS vendor, because Google provides Google Analytics (http://www.google.com/analytics/), a big data analytics, with good tracking tools. In fact, most hosting websites, like Baidu, also provide these similar big data analytics services. A mobile phone company can provide big data analytics services to the customers with smartphone [12]. For example, Mobile App Analytics (http://www.google.com/analytics/mobile/), a part of Google Analytics, is also a mobile big data analytics services provider that helps the smartphone customers to discover new and relevant users through traffic sources reports. Mobile App Analytics plays a role of integration and gets engaged through event tracking and flow visualization, and sets and tracks the goal conversions one wants most: purchases, clicks, or simply time spent on the app. More generally, many information systems have contained an analytics app as a system component to generate table, diagram or report. All these kinds of information systems can be considered as big data analytics service providers. The big data analytics services providers on the Web include Amazon, Google and Microsoft [2].

\section{Applying BASOA to BI}

This section looks at how to apply the proposed BASOA to enhance BI in some detail.

Analytics as a service (AaaS) is a relatively new concept that has emerged as a rapidly growing business sector of web analytics industry, which provides efficient web log analytic services for firm-level customers [17]. BAaaS (Big data analytics as a service), as discussed in the BASOA above, means that an individual or organization or information system uses a wide range of analytic tools or apps wherever they may be located [12]. BAaaS has the ability to turn a general analytic platform into a shared utility for an enterprise with visualized analytic services [12]. An analytics service can be available on the Web or used by smartphone. Therefore, big data analytics services include e-analytics services or web analytics services 
(WAS) [2]. BAaaS is gaining popularity rapidly in business, e-commerce, e-service, and management in recent years. For example, BAaaS model has been adopted by many famous web companies such as Amazon, Microsoft, and eBay [12]. The key reason behind it is that the traditional hub-and-spoke architectures cannot satisfy the demands driven by increasingly complex business analytics [12]. BAaaS promises to provide decision makers with visualizing much needed big data. Cloud analytics is an emerging alternative solution for big data analytics [2].

As previously defined, BI is "a set of theories, methodologies, architectures, systems and technologies that support business decision making with valuable data, information and knowledge". BASOA is an architecture for supporting business decision making with big data analytics services. The theory of big data analytics providers, brokers and requestors of the BASOA can facilitate the understanding and development of $\mathrm{BI}$ and business decision making. For example, from a deep analysis of the BASOA, an enterprise and its CEO can know who are the best big data analytics providers and brokers in order to improve his business, market performance, and competition.

We surveyed 71 information technology managers at the Association for Education in Journalism and Mass Communication (AEJMC) in Montreal during August 6-9, 2014 [2], to collect data concerning the enterprise-level acceptability of the BASOA concept. These results indicate some preliminary support for the BASOA concept of having service brokers work with service requesters and providers similar to the way private mortgage and loans work in the USA. Based on this preliminary enterprise acceptability of this BASOA model, we propose that more research be done to investigate how it could be used.

\section{Related Work and Discussion}

We have mentioned a number of scholarly researches on data analytics, big data analytics, and BI. In what follows, we will focus on related work and discussion on ontology of big data analytics, and the work of SAP as well as incorporation of big data analytics into BI.

Why does big data analytics really matter for modern business organizations? There are many different answers to this question from different researchers. For example, Davis considers that the current big data analytics has embodied the state of art current development of modern computing [27], which has been reflected in Section 2. Gandomi and Harder [7] discuss how big data analytics has captured the attention of business and government leaders through decomposing big data analytics into text analytics, audio analytics, video analytics, social media analytics, and predictive analytics. This implies that data has been classified into text data, audio data, video data, and social media data in [7].

Big data analytics and BI have drawn an increasing attention in the computing, business, and e-commerce community. For example, Lim et al [5] examine business intelligence and analytics by focusing on its research directions. They consider business intelligence and analytics (BIA) as a current form replacing the traditional BI, whereas we still consider BI and big data analytics are two different concepts, 
although they have close relationships and share some commons. Fan et al [6] provide a marketing mix framework for big data management through identifying the big data sources, methods, and applications for each of the marketing mix, consisting of people, product, place, price and promotion. However, what is the relationship between marketing intelligence and $\mathrm{BI}$ in terms of big data analytics should have been mentioned in their work [6].

Ontology has been important in computer science and artificial intelligence [16]. A basic search in Google scholar (i.e. article title and key words) reveals that there are few publications entitled "ontology of big data analytics". We then explored it and put it as a part of this research through updating our early work on data analytics, business analytics and big data analytics [2]. We explore the interrelationship among big data analytics, big data descriptive analytics, big data predictive analytics, and big data prescriptive analytics using the proposed ontology. The results reported in this paper on ontology of big data analytics and big data analytics equation are an extension and development of our early work [2] by adding optimization and ML to the equation. This is only a beginning for providing a relatively comprehensive ontology of big data analytics. In this direction, we will investigate more academic reviewed sources as a future work to develop an ontology of big data analytics with three levels for each related analytics: big data, methods and applications based on the method of Fan et al [6]. Such an investigation would become an important guide for the research and development of big data analytics and BI.

SAP, one of the leading vendors of ERP [28], has introduced its enterprise serviceoriented architecture [20, p. 383]. SAP's architecture specifies general services to enterprise services whereas our BASOA model specifies general services to big data analytics services. Big data analytics services should be a part of state-of-the-art ecommerce services [17], and then the proposed BASOA can be considered as a concrete application for the enterprise service-oriented architecture of SAP. However, SAP's enterprise systems focus on key applications in finance, logistics, procurement and human resources management as an ERP system. We conceive that our BASOA will be incorporated into the next generation enterprise systems integrating SCM, CRM, and KM systems, and e-commerce systems. This is also the motivation of our proposed BASOA.

\section{Conclusion}

This paper proposed an ontology of big data analytics, and looked at the relationship between big data analytics and BI. This paper also presented a big data analytics service oriented architecture (BASOA) and discussed how to use BASOA to enhance BI. The preliminary analysis on the collected data shows that this proposed BASOA is viable for facilitating the development of BI. The proposed approach in this paper might facilitate research and development of big data analytics, business analytics, BI, e-commerce, and e-services

In the future work, besides mentioned in the previous sections, we will analyse the foregoing collected data vigorously and explore enterprise and e-commerce acceptability of BASOA for BI. We will also explore big data analytics and its 
applications in e-commerce and cloud services, and realize BASOA using intelligent agents technology [29], where we will also look at some implementation related issues such as how to collect, store, and process big data - by whom, for what, access rights, and many more.

\section{References}

[1] C. P. Chen and C.-Y. Zhang, "Data-intensive applications, challenges, techniques and technologies: A survey on Big Data," Information Sciences, vol. 275 , p. 314-347, 2014.

[2] Z. Sun, K. Strang and J. Yearwood, "Analytics service oriented architecture for enterprise information systems," in Proceedings of iiWAS2014, CONFENIS 2014, 4 - 6 Dec 14, Hanoi, 2014.

[3] Z. Sun, S. Firmin and J. Yearwood, "Integrating online social networking with ecommerce based on CBR," in The 23rd ACIS 2012 Proceedings, 3-5 Dec, Geelong, 2012.

[4] D. Vesset, B. McDonough, D. Schubmehl and M. Wardley, "Worldwide Business Analytics Software 2013-2017 Forecast and 2012 Vendor Shares (Doc \# 241689)," 6 2013. [Online]. Available: http://www.idc.com/getdoc.jsp?containerId=241689. [Accessed $2862014]$.

[5] E. Lim, H. Chen and G. Chen, "Business Intelligence and Analytics: Research Directions," ACM Transactions on Management Information Systems, vol. 3, no. 4, Article 17, , pp. 1$10,2013$.

[6] S. Fan, R. Y. Lau and J. L. Zhao, "Demystifying Big Data Analytics for Business Intelligence Through theLens ofMarketing Mix," Big DataResearch, vol. 2, p. 28-32, 2015.

[7] A. Gandomi and . M. Haider, "Beyond the hype: Big data concepts, methods, and analytics," International Journal of Information Management 35 (2015), vol. 35, p. 137144, 2015.

[8] C. Holsapplea, A. Lee-Postb and R. Pakath, "A unified foundation for business analytics," Decision Support Systems, vol. 64, p. 130-141, 2014.

[9] R. van der Meulen and J. Rivera, "Gartner Says Worldwide Business Intelligence and Analytics Software Market Grew 8 Percent in 2013," 294 2014. [Online]. Available: http://www.gartner.com/newsroom/id/2723717. [Accessed 286 2014].

[10] V. Beal, "Big data analytics," 2014. [Online]. Available: http://www.webopedia.com/TERM/B/big_data_analytics.html. [Accessed 208 2014].

[11] M. Minelli, M. Chambers and A. Dhiraj, Big Data, Big Analytics: Emerging Business Intelligence and Analytic Trends for Today's Businesses, Wiley \& Sons (Chinese Edition 2014), 2013.

[12] D. Delena and H. Demirkanb, "Data, information and analytics as services," Decision Support Systems, vol. 55, no. 1, p. 359-363, 2013.

[13] C. Coronel, S. Morris and P. Rob, Database Systems: Design, Implementation, and Management (11th edition), Boston: Course Technology, Cengage Learning, 2015.

[14] C. Cramer, "How Descriptive Analytics Are Changing Marketing," 19 May 2014. [Online]. Available: http://www.miprofs.com/wp/descriptive-analytics-changingmarketing/. [Accessed 67 2015]. 
[15] E. Turban and L. Volonino, Information Technology for Management: Improving Strategic and Operational Performance (8th Edition), Danvers, MA: Wiley \& Sons, 2011.

[16] T. Gruber, "Toward principles for the design of ontologies used for knowledge sharing," International Journal of Human-Computer Studies , vol. 43, no. 5-6, p. 907-928, 1995.

[17] Z. Sun and J. Yearwood, "A theoretical foundation of demand-driven web services," in Demand-Driven Web Services: Theory, Technologies, and Applications, IGI-Global, 20014, pp. 1-25.

[18] H. P. Luhn, "A Business Intelligence System," IBM Journal of Research and Development 2(4), pp. 314-319, 1958.

[19] R. Sabherwal and I. Becerra-Fernandez, Business Intelligence: Practices, Technologies, and Management, Hoboken, NJ: John Wiley \& Sons, Inc., 2011.

[20] K. G. Laudon and K. C. Laudon, Management Information Systems: Managing the Digital Firm (12th Ed), Harlow, England: Pearson, 2012.

[21] A. Brust, "Gartner releases 2013 BI Magic Quadrant," 2013. [Online]. Available: http://www.zdnet.com/gartner-releases-2013-bi-magic-quadrant-7000011264/. [Accessed 142 2014].

[22] IDC, "IDC Predictions 2014: Battles for Dominance — and Survival — on the 3rd Platform," Dec 2013. [Online]. Available: http://www.idc.com/getdoc.jsp?containerId=244606. [Accessed 132 2014].

[23] M. P. Papazoglou, Web Services: Principles and Technology, Harlow, England: Pearson Prentice Hall, 2008.

[24] R. J. Kauffman, J. Srivastava and J. Vayghan, "Business and data analytics: New innovations for the management of e-commerce," Electronic Commerce Research and Applications, vol. 11, p. 85-88, 2012.

[25] J. Park, J. Kim and J. Koh, "Determinants of continuous usage intention in web analytics services," Electronic Commerce Research and Applications, vol. 9, no. 1, pp. 61-72, 2010.

[26] K. Laudon and J. Laudon, Management Information Systems-Managing the Dgital Firm, Boston: Person, 2012.

[27] C. K. Davis, "Viewpoint Beyond Data and Analytics- Why business analytics and big data really matter for modern business organizations," CACM, vol. 57, no. 8, pp. 39-41, 2014.

[28] A. Elragal, "ERP and Big Data: The Inept Couple," Procedia Technology, vol. 16, p. 242 249, 2014.

[29] Z. Sun and G. Finnie, Intelligent Techniques in E-Commerce: A Case-based Reasoning Perspective, Heidelberg Berlin: Springer-Verlag, 2004; 2010. 